\title{
Dos Notas Sobre Literatura Peruana Contemporánea
}

\author{
Mariátegui y González-Prada \\ Desvaneciendo una mistificación póstuma
}

ADA tan absurdo como pretender que las cosas cambien su esencia
con sólo recubrirlas de palabras. Método casuístico éste, tie-
ne el peor de los inconvenientes: su inutilidad; y la peor de las
lecciones: su absoluta falta de moral. Porque, por ejemplo, podrá
argumentarse todo lo que se quiera en torno a las conexiones de
Francisco de Miranda con el Foreign Office; pero de ahí sería necio
inferir que Miranda se hallaba "entregado al imperialismo británico".
Estos simplismos, para uso de intonsos, han sido, no obstante, pro-
pagados por gentes cultas, lo que probaría su insinceridad o su
ceguera.

Recuerdo, a propósito, el primer número de la revista Dialéctica, dirigida nada menos que por Aníbal Ponce, en el cual número se inŝ́ertó un artículo de Marx sobre Bolívar. Se aprovechó la coyuntura para tildar al Libertador de algo así como "sirviente del imperialismo inglés". Pero se olvidaba que a Lenin se le pudo llamar también, siguiendo idéntico camino de pueriles generalizaciones póstumas, "sirviente del imperialismo alemán", por aquello del "tren precintado". La historia, felizmente, con todas sus injusticias, no está hecha por los apresurados. Ella es fruto de juegos más apasionados, mezquinos y altos que el que emanaria de la mente de un docto en propaganda partidista de nuestros tiempos. Quizá la primera enseñanza de la historia, el primer signo revelaclor de auténtica cultura, sea nada más y nada menos que juzgar cada hecho, cada 
suceso, cada personaje, con arreglo al ambiente de su país y de su tiempo, a las posibilidades de que disponía, sin imponer a la vida una gimnasia excesiva, de la que, antes que musculaturas vigorosas, suelen derivarse jorobas y deformaciones.

Se me ha venido todo esto a las mientes al encontrar, hurgando viejos papeles de mi archivo, una carta impresa de José Carlos Mariátegui acerca de las Universidades Populares González-Prada del Perú. Hace no mucho, alguien dió en la flor de insistir en que José Carlos era una especie de antigonzálezprada, un negador o escéptico con respecto a esa figura epónima del nuevo Perú. En verdad, aquella crítica falaz y excesiva arrancaba de una pasión malsana. Como el Aprismo y Haya de la Torre tienen el nombre de GonzálezPrada al tope de sus banderas; como todo hombre que reacciona contra el conservatismo religioso, el oligarquismo político y el clasicismo hispanizante en literatura, en el Perú debe volver los ojos a González-Prada - y asi lo hemos hecho los apristas - nuestros enemigos pretenden que negar a Prada es un medio eficaz de combate, $\mathrm{y}$, apelando al testimonio de los muertos, han pretendido insinuar - y hasta decir- que José Carlos Mariátegui opinaba sobre Prada exactamente como ellos dicen opinar ahora.

Nada tan instructivo, al respecto, como escuchar la voz del propio Mariátegui. Hela aquí, en un documento fechado en Lima el 25 de julio de 1925 y dirigido a los maestros y alumnos de las Universidades Populares González-Prada, fundadas por Haya de la Torre en 1921. La carta de Mariátegui dice así :

Lima, 25 de julio de 1925.

Queridos compañeros:

Hace bien la Universidad Popular en conmemorar la noble y alta figura de González Prada. La Universidad Populat tiene el deber de mostrarse en todo instante coherente con su tradición y con su origen.

Yo creo que la Universidad Popular ha hecho de GonzálezPrada un símbolo. Haya de la Torre ha logrado que el pueblo reivindique su derecho a sentir que a él sólo le pertenece la obra y la figura de González-Prada. 
Muerto González-Prada, se propagó entre los diletantes de la inteligencia y de la cultura la moda de decirse herederos o discípulos de González-Prada. Se estaba así falsificando la verdadera personalidad del autor de Páginas libres. Poco a poco, la gloria de González-Prada iba a resultar una gloria oficial. Los subprefectos y los caciques habrian acabado por citar en sus discursos del 28 de julio y de otras efemérides, hasta hacerlos inocuos, los pensamientos más notorios de Horas de lucha y de Páginas libres. La Universidad Popular, que ha insurgido oportunamente contra este intento de deformar y de atentar contra González-Prada, no pertenece a lá decadente fauna que se esfuerza por incorporarlo en su genealogía. Pertenece al pueblo, pertenece a la Revolución, pertenece a la Vanguardia. $Y$ nosotros debemos usar su nombre hasta volverlo odioso a la burguesía y al poder. Necesitamos que sea un nombre perseguido, un nombre proscripto. Cuando la gente conservadora excluya para siempre a González-Prada de su literatura y de su retórica, habremos conseguido crear un nuevo González-Prada, y ese nuevo González-Prada será no sólo un González-Prada vivo: será sobre todo un González-Prada totalmente nuestro.

Yo habría querido escribir para la conmemoración de hoy un estudio sobre la obra del pensador que da su nombre a la Universidad Popular. Pero una conmemoración no se presta para reflexiones críticas que, por otra parte, si aspiran a ser completas y precisas no caben dentro del limitado espacio de una carta. Me toca en esta conmemoración, como a vosotros, saludar únicamente la memoria de Prada. No sería sincero, sin embargo, si no os declarase que a mi juicio nos mostraremos más dignos de Prada, que quiso ser siempre un ejemplo de severa sinceridad, si sabemos distinguir to que en la obra de Prada bay de contingente $y$ temporal $y$ lo que en la misma obra hay de eterno y perenne. No es la letra lo que en la obra de Prada posee un valor duradero: es el espíritu. En González-Prada admiramos y estimamos sobre todo el austero ejemplo moral. Estimamos y admiramos la noble, la fuerte rebeldia. Pero nuestro camino, nuestro deber, nos ordena ser más atrevidos, ser más audaces aún. "Pasad sobre mí; marchad adelante", dice Romain Rolland. $Y$ en un capítulo de la vida de su Juan Cristóbat tiene esta frase: "Muramos, Juan Cristóbal, para renacer". González-Prada si viviera nos hablaría seguramente como nos habla Romain Rolland. No reconocería en la nueva generación una generación de discípulas y herederos de su obra, si no encontrara en sus hombres la voluntad y el aliento indispensables para superar esta obra. Miraría con desdén a los repetidores mediocres de sus frases. Amaría sólo a la Juventud capaz de traducir en acto lo que en él 
no pudo ser sino idea. $Y$ no se sentiría renovado y renacido sino en hombres que supieran decir al pueblo una palabra verdaderamente nueva, verdaderamente actual.

González-Prada representó en su época el espíritu de la Revolución: ahora lo representamos nosotros. He ahí la continuidad, he ahí la solidaridad entre la obra que él emprendió y la que nosotros nos proponemos cumplir. He ahí el nexo histórico que inspira y motiva este homenaje. González-Prada denunció todas las miserias del pasado, todas las tristezas del presente. No tuvo miramientos cobardes ni eufemismos diplomáticos. Seamos como él en la protesta.

\section{José Carlos Mariátegui.}

No me queda sino repetir, frente a la mendacidad de quienes pretenden falsificar el sentimiento y las palabras de Mariátegui con respecto a González-Prada: "Seamos como él en la protesta".

\section{"Panorama hacia el alba": testimonio y clave}

Al Concurso de Novelas Latinoamericanas, organizado en Nueva York por la Casa Farrar and Reinhardt, en colaboración con la Unión Panamericana, presentó el Perú dos autores: Ciro Alegria, el vencedor continental, y su El mundo es ancho y ajeno, y Alberto Ferrando, con su Panorama hacia el alba. A Ciro Alegría lo recomendó el Jurado de Chile, al par que premiaba una novela chilena de Eugenio González, fino observador y pulcro estilista, de cuya pluma han salido tres libros: Más afuera, Hombres y Destino.

No voy a reiterar comentarios sobre El mundo es ancho y ajeno. Los he hecho ya repetidas veces, no bien se supo el otorgamiento del premio. Conceptúo a Ciro Alegría, no ahora en que todos vuelven los ojos a él, sino desde La serpiente de oro y Los perros hambrientos (para mi gusto lo más novelesco esto último), como el primer novelista peruano: primero en el tiempo y en el rango. Pero, no por eso se debe dejar de mirar el contenido del libro de Ferrando, máxime cuando se encuentra en la encrucijada del elogio incondicional o del desdén injustificable. Panorama hacia el alba es una novela superior a muchas que se han escrito en el Perú. 
Sus deficiencias y sus méritos provienen de una misma veta, de un mismo cauce: el exceso de ese mal llamado criollismo que, a falta de posibilidad de afrontar cuestiones trascendentales, viene inficionando la literatura peruana desde hace diez años.

Es posible que muchos se llamen a enojo por lo que aquí diga. Peor sería callar un comentario que, en el más infeliz de los casos, ha de servir para que los críticos y los creadores (o rapsodas) examinen un instante lo que pueden y deben decir. Se ha mistificado a tal punto la crítica entre nosotros, los peruanos, que he llegado a leer, con respecto a una correcta descripción del país, que era un libro comparable con el Facundo de Sarmiento. No se trata de que Sarmiento constituya una cumbre insuperable. De lo que se trata es de que conservemos cierta mesura educadora, cierta capacidad de discernimiento y que no confundamos nuestras predilecciones afectivas con los juicios de valor, indispensables para una recta y fecunda educación de la mentalidad nacional.

Pandrama hacia el alba relata la historia de un "faite", cuyo anecdotario empieza en la costa, en el puerto del Callao, entre chabetazos, y termina, casado y al borde de la opulencia, en la selva. Recorre - si hablamos geográficamente- las tres zonas territoriales, lo cual si bien puede ser una excelente guía turística, no debe, por fuerza, constituir un mérito literario, aunque el Jurado opine lo contrario. En torno a la vida del protagonista, ctyo primer capítulo bordonea el tema del vientre abierto "como caballo de pica" de su contrincante, sigue con otro duelo a chabeta; se prolonga en algunos episodios de amor; en "faiterías" de barrio; en aventuras en la sierra; en una mujer adinerada que se enamora del vagabundo; en dos asesinatos, una violación y, por fin, la fortuna; - en torno a la vida del protagonista, a mi juicio, mero pretexto para lo demás, Ferrando taracea dichos, cantares, refranes, giros, coplas criollas, o sea, zambas, pues no se trata de un criollo como el de Argentina, basado en su arraigo en la tierra nativa, sino en su mayor concordia con las costumbres de jarana, con la fiesta típica, con el pisco y la marinera. El criollo del Perú equivale a jaranista desfachatado y zumbón.

$\mathrm{Y}$ estos son los principales defectos - y cualidades - de Panorama hacia el alba. Y si los menciono, no lo hago con ánimo de censura, sino de conversación, a fin de que nos revisemos un instante 
el alma y su expresión, y, sobre la base de hechos concretos, ensayemos un camino literario que no se confunda, como ocurre, con el folklore.

Me está pareciendo que mucha parte de la literatura peruana adolece de folklorismo. Las causas son fáciles de explicar, pero la tendencia puede y debe superarse. Rastrear motivos nacionales no implica folklore. Sería absurdo decir que $L a$ vorágine de Rivera se rinde ante el folklore. Nada de eso. La realidad está estilizada, enaltecida a la cima del arte. En El mundo es ancho y ajeno de Alegría, en Don Segundo Sombra de Güiraldes y en 4 años a bordo de mi mismo de Zalamea Borda, lo nativo se fortifica con la estética. $\mathrm{E} 1$ escritor interpreta, no rapsodia. Por cierto, la interpretación entraña generalizaciones y ahondamientos más allá de lo circundante, de lo inmediato. Para' llegar a dominar el procedimiento se requieren varios ingredientes, uno de ellos completa libertad de expresión, desaparición de todo tabú, no ya a lo estrictamente literario, sino también a los otros cambios de la inteligencia y de la vida. Porque, siendo el escritor un compendio de la existencia de un pueblo, si se le veda uno de los manantiales, se le trunca y todo él sufre a consecuencia del menoscabo.

José Ferrando, para mí una gratísima sorpresa, posee indudables méritos de narrador. Confieso que la lectura de su libro ha sobrepasado mis expectativas, con mucho. Más todavía: a través de algunos versos suyos publicados después de su triunfo en Lima, me habia formado un antejuicio peyorativo. Panorama hacia el alba me ha traído la consoladora certeza de que además de Ciro Alegría, el primero sin duda, y de otros relatistas de enjundia, tenemos otro más en Ferrando. Ojalá no se pierda' como parece haberse perdido Ernesto Reyna, ni se quede en merodeos zambos como algún afortunado novelista de hace una década. Ferrando, no obstante su cualidad de narrador, $y$ hasta un innegable graficismo imaginativo, no ha conseguido vencer las limitaciones de su medio, y ha caído en eso que, lejos de ser criollismo, resulta folklore, utilizando un lenguaje que se queda en la germanía o el caló, sin significar el aporte recio de metáforas y palabras "constructivas" que se ve en Fernando Ghilardi, Alegría, Gallegos, Padrón, Azuela, etc.

Nada tan gráfico, desde luego, como giros así: "Como que era del pelo, estaba pintada al duco, de romántico matiz encanelado"; 
"Pese.a la distancia que medía entre el negro y la zamba era 'primera monta' de Bárbara, la 'cintura de cobre' por sus sabias caderas opulentas"; "Lo hicieron, él por gana, y ella, por detalle". De un acto dice que fué "violento como un tiro penal". Esta fruición por las metáforas futbolísticas, signo característico de Lima, donde el futbol va reemplazando al toreo, se manifiesta también en este otro giro: "Rossi, cortándose hacia el arco, se vino dribleando e hizo un centro preciso en esta frase"; "Sobre las columnas de sus gambas", manera de llamar a las piernas, no a lo italiano, sino a lo argentino, a través del futbol (gamba, gambeta, gambetear); Miró "basureando a su rival", término muy gráfico y limeño; "Me sonó", imitación argentina, importada al Perú a través de las revistas porteñas. (Lo típico es "me cayó", abreviación de "me cayó la quincha encima").

Al lado de estos modismos y de las denominaciones carcelarias, de mera germanía, Ferrando incurre, a veces, en estiramientos de lenguaje, un poco rebuscados. Verbigracia: "esa mujer era un imperativo categórico a la violación"; "luces escintilantes"; "sus rememoraciones se velaron al fulgor de luciérnagas que rubricó la colilla en su postrera parábola hasta las aguas procelosas"; los "lambrequines escarolados de las volutas de su cabello endrino". Lo anotado revela poco ejercicio literario. Ferrando, a medida que recupere su práctica, que se estrene tirando al arco, como le gustaría decir, llegará a rubricar goles de impecable factura, es decir, tiros violentos y precisos, sin mucho dribling, con puntería, oportunidad y coraje, que en literatura se traduce en esto solo: sencillez.

Para un investigador filológico hay mucho material en la novela que comento. "Esso que me lo digas, pero que me lo carambolees", etc., son contribuciones al folklore y a la lingüística, a la dialectología. Pero, la literatura tiene otro campo, no sé si más alto, en todo caso más intenso. De ahí que, por muy cotidiana que sea la expresión, no se adecúa ni al momento vital que retrata, ni al buen gusto, aquel decir del injerto que pretende poseer a la mujer del protagonista: “¿por qué no puedo yo tener mi alita en este lomo con todo?” Imagino que los costumbristas han debido regocijarse con eso; los críticos y los lectores avezados, no.

Comprendo que hacer reparos a un libro, en medios no habituados a la crítica, o en donde se afirma o se niega, rotundamente, ha de causar alguna sorpresa. Para el lector peruano las líneas anterio- 
res sonarán a censura. No es verdad. Repito, y no por dorar la pildora, sino porque lo creo de veras, que Ferrando me ha producido una sorpresa gratísima. En él hay indudablemente un descriptor, pero no todavía un escritor. ¿Por qué no se le ayuda diciéndole a la cara lo que se murmura en los rincones? ¿Por qué no contribuir a su depuración, como los buenos compañeros y los buenos entrenadores, pidiendo que corrija to que debe corregir, ya que se sabe que posee punch suficiente para demoler adversarios y se le sabe leal consigo mismo? Un hombre que, no obstante sus aficiones literarias, ha tenido el heroísmo de estarse callado veinte años, merece el homenaje de la sinceridad. A José Ferrando, pues, en el Perú, a donde no consigo llegar; donde si pudiera le diría mil comentarios más que me sugiere su libro; a José Ferrando, pues, mi homenaje y (homenaje también) mis reparos.

Siga usted escribiendo, José Ferrando. El alba que usted anuncia es la suya propia. Enhorabuena.

Luts Albérto Sánchez, Santiago. 